\title{
Business Process Management
}

\section{An introduction to the special focus issue}

\author{
DOI 10.1007/s12599-012-0228-2
}

\section{The Authors}

\author{
Jörg Becker \\ European Research Center \\ for Information Systems \\ University of Münster \\ Münster \\ Germany \\ becker@ercis.uni-muenster.de \\ Michael Rosemann ( $\varangle$ ) \\ Information Systems School \\ Science and Engineering Faculty \\ Queensland University \\ of Technology \\ Brisbane Qld 4000 \\ Australia \\ m.rosemann@qut.edu.au \\ Maximilian Röglinger \\ FIM Research Center Finance \\ \& Information Management \\ University of Augsburg \\ Augsburg \\ Germany \\ maximilian.roeglinger@wiwi.uni- \\ augsburg.de \\ Michael zur Muehlen \\ Howe School of Technology \\ Management \\ Stevens Institute of Technology \\ Castle Point on Hudson \\ Hoboken, NJ 07030 \\ USA \\ mzurmuehlen@stevens.edu
}

Published online: 2012-08-29

This article is also available in German in print and via http://www. wirtschaftsinformatik.de: Becker J, Rosemann M, Röglinger M, zur Muehlen $M$ (2002) Prozessmanagement. Eine Einleitung zum Schwerpunktthema. WIRTSCHAFTSINFORMATIK. doi: 10.1007/s11576-012-0333-3.

(C) Gabler Verlag 2012
The management and improvement of business processes are a core topic of the information systems discipline. The persistent demand in corporations within all industry sectors for increased operational efficiency and innovation, an emerging set of established and evaluated methods, tools, and techniques as well as the quickly growing body of academic and professional knowledge are indicative for the standing that Business Process Management (BPM) has nowadays. During the last decades, intensive research has been conducted with respect to the design, implementation, execution, and monitoring of business processes. Comparatively low attention, however, has been paid to questions related to organizational issues such as the adoption, usage, implications, and overall success of BPM approaches, technologies, and initiatives. This research gap motivated us to edit a corresponding special focus issue for the journal BISE/WIRTSCHAFTSINFORMATIK.

We are happy that we are able to present a selection of three research papers and a state-of-the-art paper in the scientific section of the issue at hand. As these papers differ in the topics they investigate, the research method they apply, and the theoretical foundations they build on, the diversity within the BPM field becomes evident. The academic papers are complemented by an interview with Phil Gilbert, IBM's Vice President for Business Process and Decision Management, who reflects on the relationship between business processes and the data flowing through them, the need to establish a process context for decision making, and the calibration of BPM efforts toward executives who see processes as a means to an end, rather than a first-order concept in its own right.

The first research paper is authored by Sven Overhage, Dominik Birkmeier, and Sebastian Schlauderer from the University of Augsburg, Germany. The authors deal with the quality of business process models and present the detailed and comprehensive 3QM framework, a theoretically well-founded quality model that includes criteria, metrics, and measurement procedures. The paper follows a design science research approach. The applicability of the quality framework has been demonstrated using case studies. An additional survey attests the utility of the quality framework. The framework is a sound consolidation and extension of the comprehensive body of previous knowledge dedicated to the quality of business process models.

Nils Urbach from the EBS Business School, Germany, and Tobias Würz from Horváth \& Partners have authored the second research paper presented in this special focus issue. The paper is situated in the process outsourcing domain and proposes a reference framework for information technology outsourcing steering processes. The framework aims to prevent outsourcing failures that stem from mistakes in the operational steering of outsourcing providers, which particularly happen in companies with little experience in implementing larger outsourcing programs. Just like the first research paper, this contribution follows the design science research paradigm. The reference framework was evaluated by means of expert interviews and field studies.

In the third research paper, Markus Schäfermeyer, Christoph Rosenkranz, and Roland Holten from the Goethe University Frankfurt, Germany, investigate the relationship between standardization effort, business process complexity, and business process standardization. Based on a survey among more than two hundred BPM experts, the authors show that business process complexity is a determinant of the standardization effort and provides constraints for business process standardization.

The state-of-the-art contribution is authored by Florian Johannsen and Susanne Leist from the University of Regensburg, Germany. The paper deals with the question whether Wand and Weber's decomposition model that was originally defined for the decomposition of information systems can be adapted to the decomposition of business process models. With this research, the authors intend to provide a first theoretical foundation for guidelines regarding the structured decomposition of business process models. 
Finally, we would like to thank all authors and reviewers for their motivation, contributions, and endurance. In sum, we received more than thirty manuscripts for the special focus issue and invited about 120 reviews. We are happy that so many of our global colleagues were engaged in the compilation of this special focus issue. We are confident that the selected papers provide inspiring insights for academics and BPM professionals alike as well as an impetus for future BPM research and improved BPM capabilities in practice. 